\title{
EFFECT OF AGE ON THE RECRUITMENT OF OOCYTES IN THE CLIMBING PERCH, ANABAS TESTUDINEUS (BLOCH)
}

\author{
AHM Shafiullah Habib and Baharul Hoque ${ }^{1}$ \\ Department of Zoology, Jagannath University, Dhaka, Bangladesh
}

\begin{abstract}
Effect of age on the recruitment of oocytes in Anabas testudineus has been studied. For age determination opercular bones, otoliths and scales were collected from 210 adult females weight ranging between $18.0 \mathrm{~g}$ and $135.0 \mathrm{~g}$ and length between $8.5 \mathrm{~cm}$ and $20.5 \mathrm{~cm}$. The scatter points of opercular bone length, scale length, and otolith length against the fish length showed linear relationships. The high values of coefficient of correlation $(r)$ indicated that all hard parts grew proportionately with the corresponding growth of the fish. The marginal open zone in all hard parts had minimum width during the months of June and July indicating that the age ring might have been formed in the season immediately preceding these months due to spawning. The age rings were annulus in nature since the fish was found to spawn once in a year. Recruitment of oocytes were not affected by the age of the fish. No statistical significant difference was observed between the number of oocytes contained in the ovary of fishes falling into two different groups of the same body length.
\end{abstract}

Key words: Anabas testudineus, opercular bone, otolith, scale, annulus, age determination, oocyte recruitment.

\section{INTRODUCTION}

In fishery biology the annual rings on certain hard parts of fish especially opercular bones, otoliths, scales are used to determine the age and growth of a fish. Considering the importance of studying age and growth numerous scientists in Bangladesh and other countries of the world conducted investigation on age and growth of many fish species. Among them Hile (1936), Le Cren (1958), Shafi and Maitland (1971), Khan and Siddique (1973), Shafi et al. (1977), Hoque and Ali (1984), Desai and Srivastava (1990), Azadi and Quddus (1995), Choat and Axe (1996), Villaneuva and Balbine (1997) and Waldron and Gerneke (1997), Hoque and Habib (2003) are notable. Age, an important biological factor, has been reported to influence the sensitivity and activity of the glands which in turn control the oogenic activities and spawning (Balsare, 1973; Kapoor, 1977). For age determination growth zones or growth 'checks' which appear on different hard parts of fishes are interpreted and counted. Those that are considered to be formed annually are called 'year marks', or 'annual marks', or 'annual rings' or annuli (Bagenal and Tesch, 1978). These are formed during alternative periods of faster and slower growth or no growth at all and reflect various environmental or internal influences (Bilton, 1974). The aim of the present investigation is to find out the influence of age on the manner of recruitment of oocytes in Anabas testudineus. However, the

${ }^{1}$ Department of Zoology, University of Chittagong, Chittagong-4331, Bangladesh. 
degenerating or atretic oocytes (AF) were also brought under consideration. For A. testudineus no established aging method was found and thus opercular bone, otolith and scale methods were used for age determination.

\section{MATERIAL AND METHODS}

A total number of 210 adult female $A$. testudineus with body weight ranging from $18.0 \mathrm{~g}$ to $135.0 \mathrm{~g}$ and body length from $8.5 \mathrm{~cm}$ to $20.5 \mathrm{~cm}$ was used. Live fish samples were collected monthly between August '98 and July '99 from local markets around Chittagong city. At autopsy firstly the total body lengths and the total body weights were recorded. For age determination opercular bones, otoliths and scales were collected and then cleaned and stored properly. When opercular bones were dry the age rings on the opercular bones, if present, were visible and it was found that these rings were much clearer after some months of storage. The maximum distance between centre and its margin was taken as the length of opercular bone. When opercular bones were viewed against light, contrasting layers of ossification was observed giving the impression of rings between two layers. Age was then estimated by counting the number of rings completed on the opercular bones.

Otoliths were removed by a lateral dissection on the head of each fish. Among the otoliths only the largest, the sagitta, was used for age determination. Before examination otoliths were ground finely following the acid contact method (Sinha and Jones, 1967). Otoliths were placed in water in a petri dish and light was then transmitted from below through it. When transmitted light is passed through otolith the opaque zones appear a shadowy rings and the hyaline zone as bright light rings. Age was then determined by counting the number of rings in the otoliths. A millimeter scale determined the length of each otolith. The maximum distance between one edge to the other was considered as the length of the otolith and was finely measured with the help of millimeter scale.

Four to five scales were collected from below of the lateral line and posterior of the dorsal fin. The maximum distance between the focal point (focus) and the anterior margin of the scale was taken as the radius of the scale. The margins of the scales were observed under a dissecting binocular microscope. Age was determined by counting the completed number of rings found on the scales.

Relationship among the hard parts namely opercular bones, otoliths and scales against body length were established statistically through linear regression. Age groups were considered as 0+ (less than one year), 1+ (less than two years), 2+ (less than three years), and so on. Photographic records of the structures used were kept following the suggestions given by Mina (1965), Banks and Irvine (1969). 


\section{RESULTS AND DISCUSSION}

\section{A. Age determination from hard parts}

Opercular bone: The outer side of the opercular bone of A. testudineus was convex. The convex side of the bone is rough and the concave side is smooth. The free edge of the opercular bone was serrated and spines at the free edge of the opercular bone were varied in size and number depending upon age of the fish (Plate 1a \&1b). Age was estimated by counting the number of marks completed on it, if any.
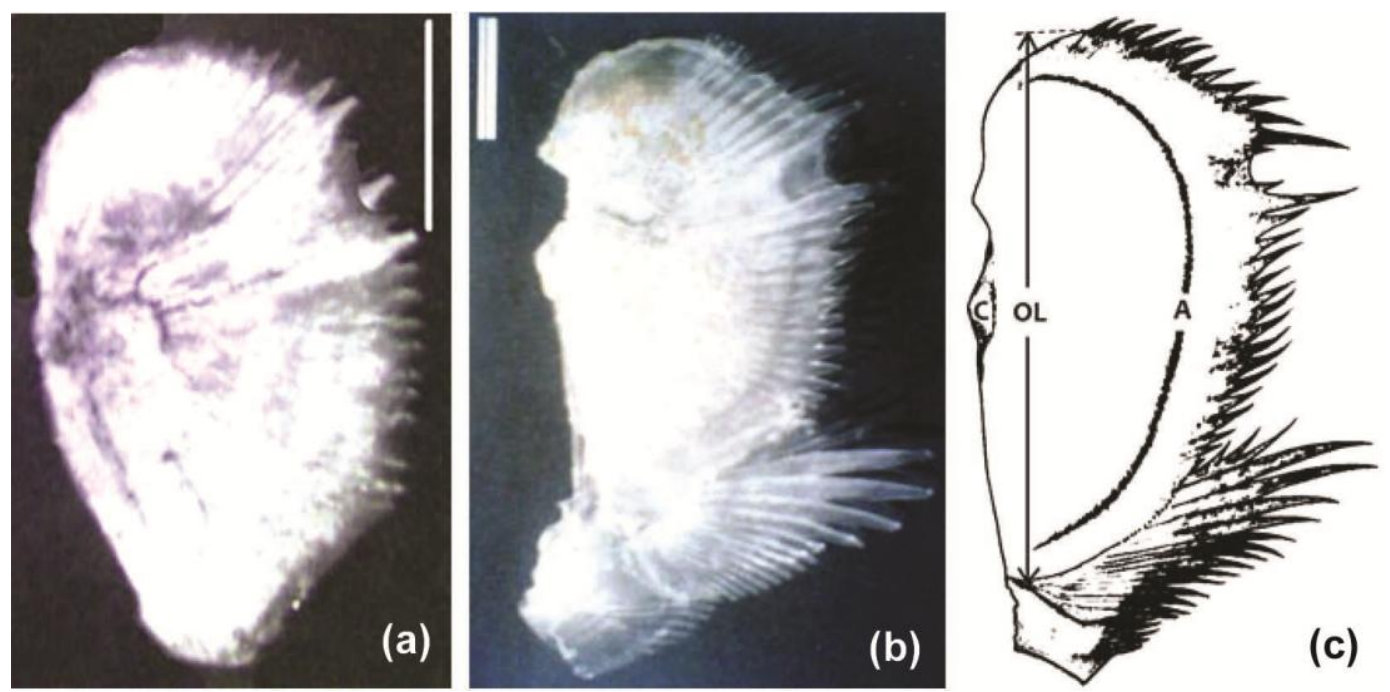

Plate 1. Opercular bones of Anabas testudineus; (a) opercular bone less than one year old without any annulus (scale line $5 \mathrm{~mm}$ ), (b) age 1+ year with an annulus (scale line 5mm), (c) diagrammatic with an annulus showing opercular length (OL) and annulus (A).

Relationship between fish length and opercular bone length: The scatter diagram of fish length and opercular bone length showed a linear relationship (Fig. 1) and the regression equation for the relationship was found as:

$$
Y=2.9315+1.3692 X
$$

Where, $X$ was independent variable and $Y$ was dependent variable. The coefficient of correlation $(r)$ was 0.9909 (P < 0.05). A direct relationship of high degree of significance between opercular bone length and fish length has been, thus, justified by the high value of coefficient of correlation. Since, opercular bone as a hard part showed proportional growth it was considered as a tool for age determination.

Otolith: The largest otolith, the sagitta was moderately large, compressed, curve and oval in shape (Plate $2 \mathrm{a} \& 2 \mathrm{~b}$ ). The inner side was smoother than the outer side. Edge of the otolith was wavy and bears distinct growth marks. Age was estimated by counting the rings on it, if any. 

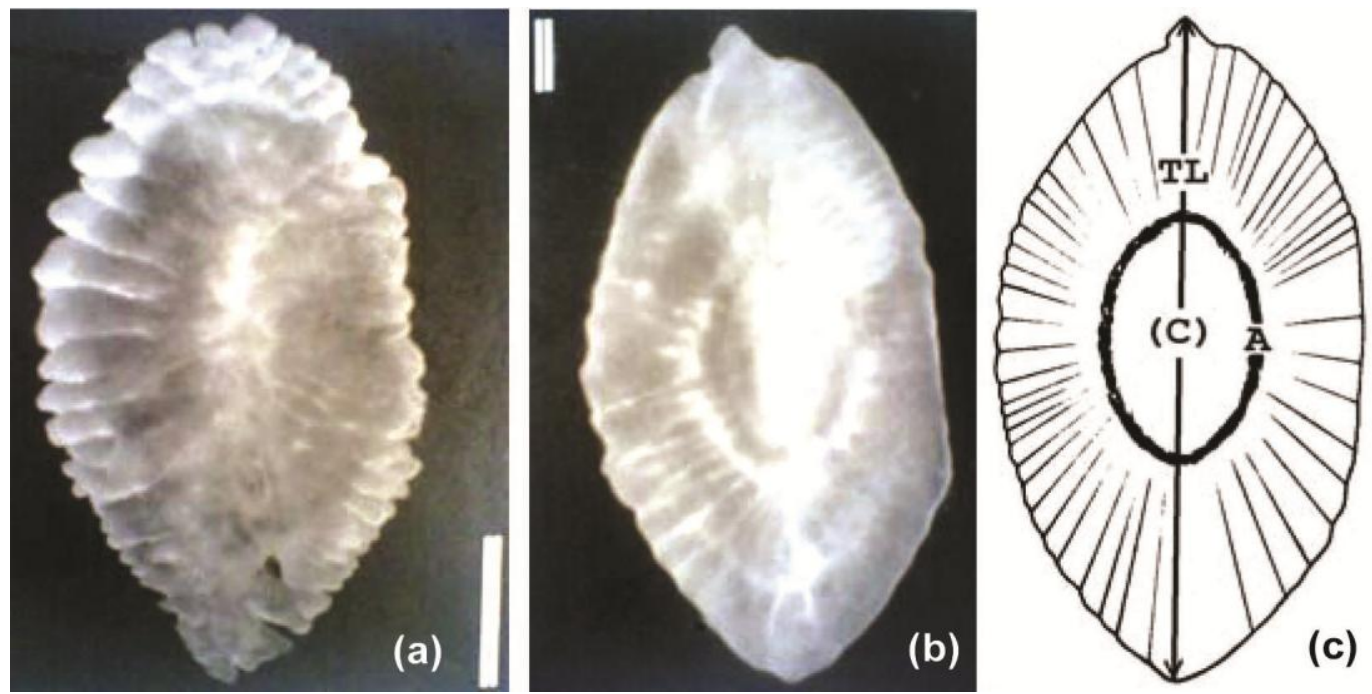

Plate 2. Otoliths of A. testudineus; (a) otolith less than one year old without any annulus (scale line $1 \mathrm{~mm}$ ), (b) age 1+ year with an annulus (scale line $1 \mathrm{~mm}$ ), (c) diagrammatic showing total length (TL), centre (C) and annulus (A).

Relationship between fish length and otolith length: The scatter diagram of otolith length on body length showed a linear relationship (Figure 2). The regression equation for the relationship was:

$$
Y=-0.0018+0.5113 X
$$

Where, $Y$ was dependent variable and $X$ was independent variable. The coefficient of correlation $(r)$ is $0.9977(\mathrm{P}<0.05)$, which was highly significant. Such fairly high value showed a close relationship between otolith length and fish length. This direct positive correlation between body length and otolith length formed a basis for using otolith to determining the age of the fish.

Scale: Scales were ctenoid in type and more or less circular in shape. Moreover, many spines were present at the posterior free area of the scale (Plate $3 a \& 3 b)$. The scale is flat and the inner side was smooth but ridges or circuli covers the outer side of the scale. These circuli are nearly concentric surrounding a central spot or focus. A zone of closely spaced circuli has been considered as the annulus. The annuli were then counted to determine the age of the fish.

Relationship between fish length and scale radius: The regression of scale radius on fish length gave a straight-line relationship with a high degree of significance (Fig. 3). The regression equation found between fish length and scale radius was:

$$
Y=1.2322+0.1708 X
$$

Where, $Y$ was dependent variable and $X$ was independent variable. The coefficient of correlation $(r)$ was found for this relationship is $0.8135(\mathrm{P}<0.05)$. 
Thus, a direct proportion had been accepted and was justified by the high value of correlation coefficient $(r)$.
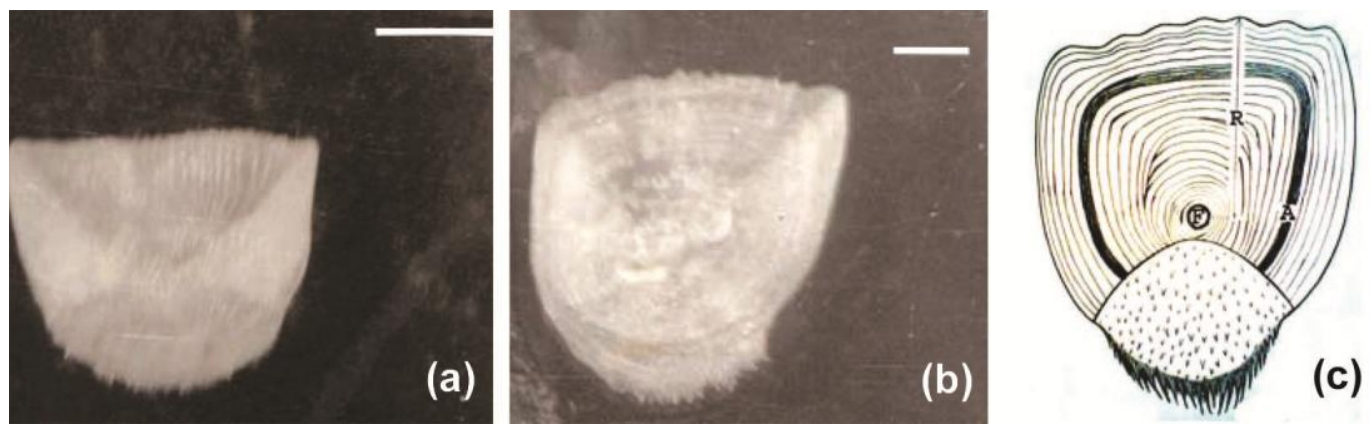

Plate 3. Ctenoid scales of A. testudineus; (a) age less than one year old without any annulus (scale line $2 \mathrm{~mm}$ ), (b) age $1+$ year with an annulus (scale line $2 \mathrm{~mm}$ ), (c) diagrammatic showing foucus (F), radius (R) and annulus (A).

Ring formation and aging: Estimation of outer margin of the hard parts indicated that the ring had been formed any time between May and July with a high frequency around June-July. Ring formation tooks place earlier in smaller fishes and later in large fishes during the period. In all the hard pats annulus appeared as a distinct ring that were parallel to the general contour of the hard parts. An annulus was considered to be true only when it was present in all the hard parts of the same fish. The annuli were formed due to spawning and thus were considered as spawning mark. A. testudineus spawns once in a year during monsoon and it starts at the end of the first year when the fish mature.

Age rings on hard parts were checked and counted for determining age of $A$. testudineus. Data on the number of annulus found in the hard parts corresponding age and the frequency was presented in the Table 1. Out of 210 fishes 5 fishes were found to be in their first growing season and thus belong to the age group $0+$. No annulus was found in the opercular bone of these fishes (Plate 1a). Table 1 shows that majority of fishes used for age determination are in the second growing season, i.e. in the age group 1+. These fishes have only one age mark on their opercular bones (Plate 2a). On the otoliths of abovementioned 5 fishes there was no complete annulus (Plate 2b). But rest of the fishes was found to bear distinct annulli (Plate 2b). Similar result was also found in case of scales where 5 fishes did not bear any age mark on the scales (Plate 3a) where as rest of the scales bear distinct year mark (Plate 3b). Out of 205 fishes having annulus on their hard parts 125 fishes were found to carry only one annual mark and 80 fishes have 2 distinct annual marks. Fishes having same body length but falling into different age group were also found. 
Table 1. Data on the age estimated by opercular bone, otolith and scale method of A. testudineus.

\begin{tabular}{lcc}
\hline Number of annuli & Age (year) & Number of fish \\
\hline Nil & Less than one year $(0+)$ & 5 \\
One & Less than two year $(1+)$ & 125 \\
Two & Less than three year $(2+)$ & 80 \\
\hline
\end{tabular}

The plus sign refers to growth beyond the annual mark(s).

Table 2. Data on the age, number of fish and average length at age and length ranges of $A$. testudineus.

\begin{tabular}{lccc}
\hline Age & $\begin{array}{c}\text { Number of fish } \\
\text { (frequency) }\end{array}$ & $\begin{array}{c}\text { Average length at } \\
\text { age }(\mathrm{cm})\end{array}$ & $\begin{array}{c}\text { Length range } \\
(\mathrm{cm})\end{array}$ \\
\hline Less than 1 year $(0+)$ & 5 & Shorter than 10 & 10 \\
1 year $(1+)$ & 125 & 10.5 & $10-14$ \\
2 year $(2+)$ & 80 & 14.7 & 15 \\
\hline
\end{tabular}

\section{B. Effect of age on oocytes recruitment}

In A. testudineus the recruitment of oocyte was not affected by age (Table 3 and 4). Table 3 clearly shows that recruitment of first growth phases (FGP) oocytes was not affected by age. Differences found in the number of FGP oocytes recruited in the ovaries of fishes of two different age groups $(1+$ and $2+)$ but of same body length were not statistically significant.

Table 3. Data on body length, age and number of first growth phase (FGP) oocytes in the ovaries of $A$. testudineus.

\begin{tabular}{lcc}
\hline $\begin{array}{l}\text { Age group } \\
\text { (Number of fish) }\end{array}$ & $\begin{array}{c}\text { Body length } \\
(\mathrm{cm})\end{array}$ & $\begin{array}{c}\text { Number of FGP oocytes } \\
\text { per female }\end{array}$ \\
\hline $1+(5)$ & 15.0 & 428360 \\
$2+(5)$ & 15.0 & 433240 \\
\hline
\end{tabular}

Data on body length, age and number of oocytes in different phases of oocytes namely first growth phase (FGP), medium-sized second growth phase (MSGP), large-sized second growth phase (LSGP) found in the ovaries of the fishes collected in the month of June, breeding season, are shown in Table 4. It is evident from the table that as long as body length of the fishes remained same no significant difference in the number of oocyte was occurred despite differences in their age. 


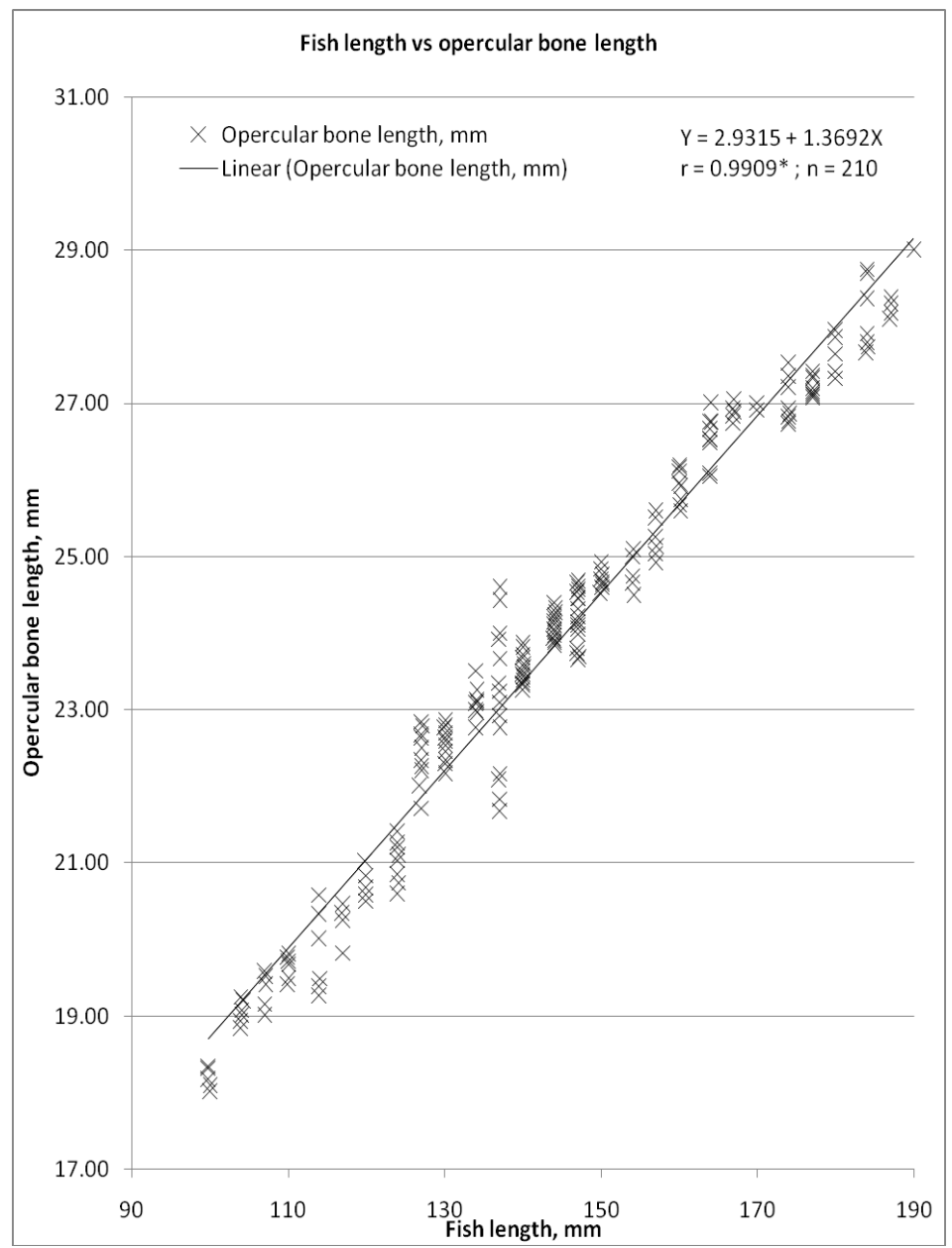

Fig. 1. Highly significant positive correlation between fish length and opercular bone length in Anabas testudineus. *Significant at 5\% level of significance.

Table 4. Data on body length, age and number of oocytes in different phases in the ovaries of $A$. testudineus.

\begin{tabular}{lccccc}
\hline \multirow{2}{*}{$\begin{array}{l}\text { Age } \\
\text { group }\end{array}$} & $\begin{array}{c}\text { Number of } \\
\text { fish }\end{array}$ & $\begin{array}{c}\text { Body length } \\
(\mathrm{cm})\end{array}$ & \multicolumn{3}{c}{ Number of oocytes per female } \\
\cline { 4 - 6 } & & & $\begin{array}{c}\text { FGP } \\
\text { (stage I \& II) }\end{array}$ & $\begin{array}{c}\text { MSGP } \\
\text { (stage III) }\end{array}$ & $\begin{array}{c}\text { LSGP } \\
\text { (stage IV) }\end{array}$ \\
\hline $1+$ & 5 & 14.7 & 95140 & 7620 & 42615 \\
$2+$ & 5 & 14.7 & 98985 & 8550 & 45575 \\
\hline
\end{tabular}

Values are mean. FGP means First Growth Phase egg. MSGP means Mediumsized Second Growth Phase egg. LSGP means Large-sized Second Growth Phase egg. 
Rao (1961) reported that ovulation rate is significantly affected by age and observed that the ovulation rate starting from adolescent sterility rises rather rapidly to its highest point and gradually falls with advancing age to senile sterility.

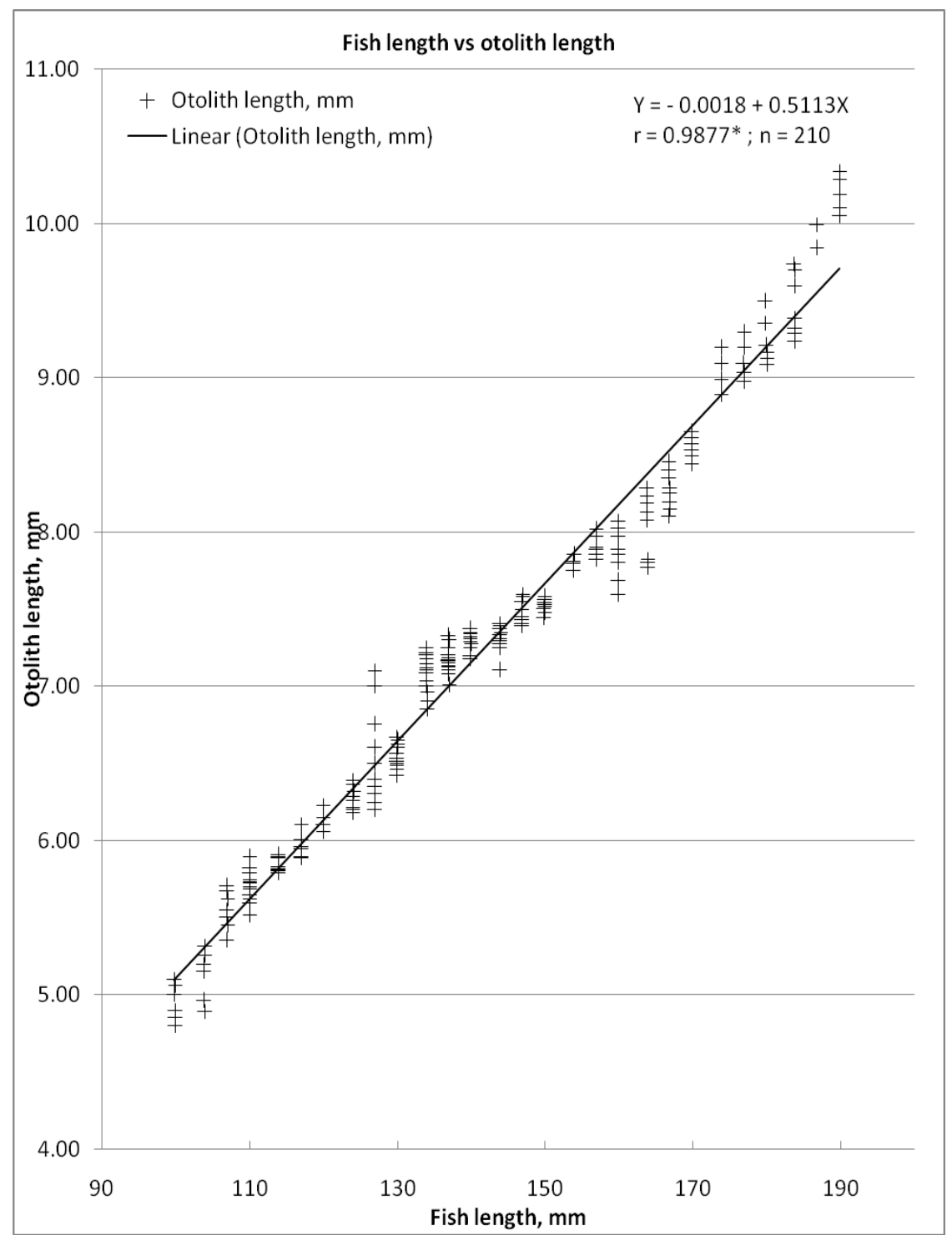

Fig. 2. Statistically significant and direct correlation between body length and otolith length in Anabas testudineus. *Significant at 5\% level of significance. 


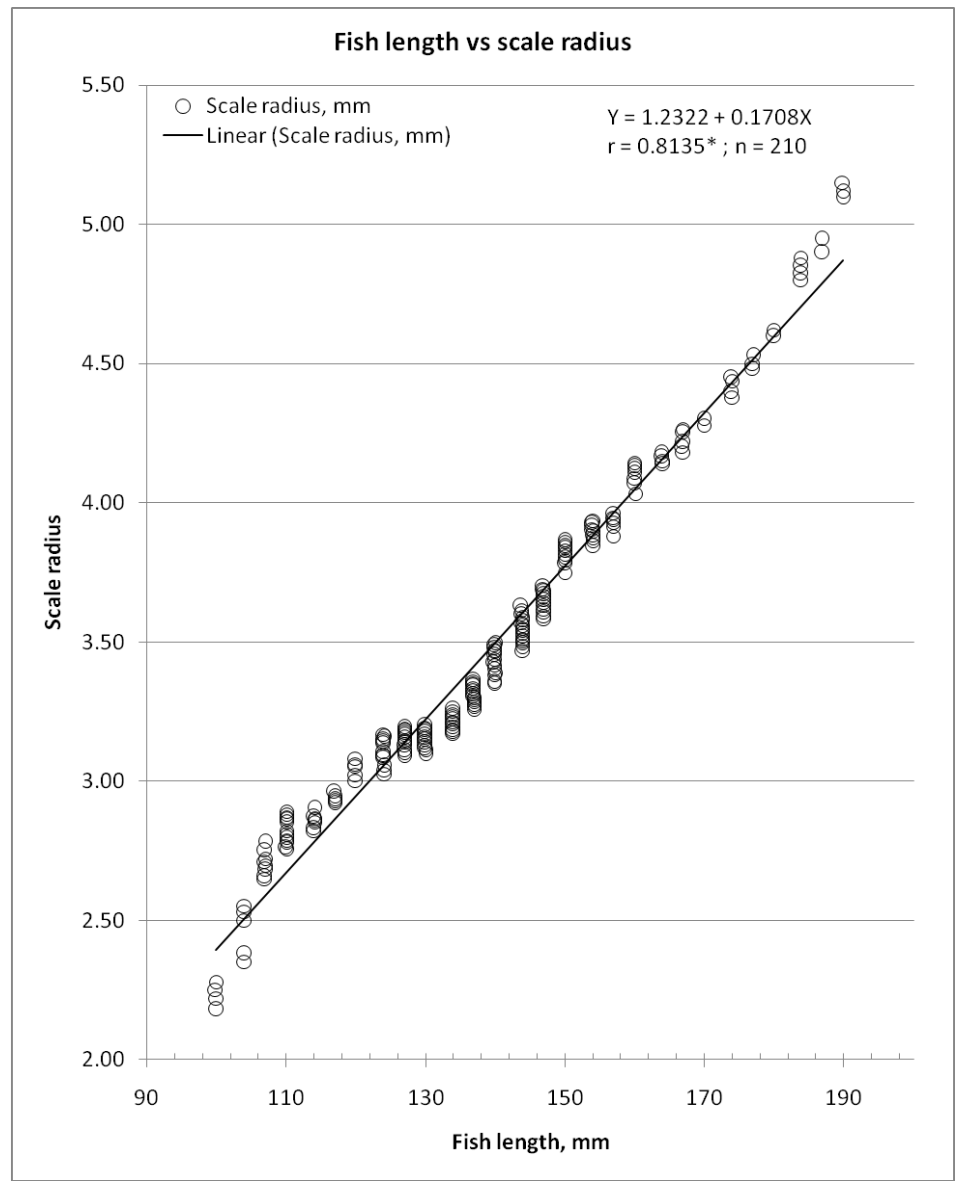

Fig. 3. Statistically significant and direct correlation between fish length and scale radius in Anabas testudineus. *Significant at 5\% level of significance.

\section{CONCLUSION}

From the present study on the effect of age on the recruitment of oocytes, it is clear that there is no significant difference in the number of oocytes between two age group of female fish but with same body length.

\section{LITERATURE CITED}

AZADI, M. A. and QUDDUS, M. M. A. 1995. Age and growth of a carp, Labeo calbasu (Ham.) from the Kaptai reservoir, Bangladesh. Chittagong Univ. Stud. Part II. Sci. 19(1): 7-17.

BAGENAL, T.B. and TESCH, F.W. 1978. Methods for assessment of fish production in freshwaters. T. Bagenal (ed.) I.B.P. Handbook No. 3, 3rd ed. Blackwell Scientific Publications, Oxford, 365pp.

BANKS, J.W. and IRVINE, W. 1969. A note on the photography of fish scales, opercular bone and otoliths using and enlarger. J. Fish Biol. 1: 25-26. 
BELSARE, D.K. 1973. Studies on the development of endocrine glands in fishes, IV. Development of Gonads in Clarias batrachus. Zool. Jb.Anat Biol., 93: 165-174.

BILTON, H. 1974. Effect of starvation and feeding on circulus formation on scales of young sockeye salmon of four racial origins and one race of kokanee, cocho and chinook salmon. In aging of fish. pp 40-70 (Ed T.B. Bagenal) Unwin Brothers, old working 234pp.

CHOAT, J.H. and AXE, L.M. 1996. Growth and longevity in canthurid fishes: an analysis of otolith increments. Marine Ecology Progress Series, 134(1-3): 15-26.

DESAI, V.R. and SRIVASTAVA, N.P. 1990. Studies on age, growth and year selectivity of Cirrhinus mrigala (Hamilton) from Rihand reservoir, Uttar Pradesh. Indian J. Fish., 37(4): 305-311.

HILE, R. 1936. Age and growth of Cisco leucichthys artedi Le suercur in the lake of north eastern highland. S. Bull. U.S. Bur. Fish. 48: 211-317.

HOQUE, B. and ALI, S.T. 1984. Determination of the age and growth of Catla catla (Ham.) opercular bone. J. Asiat Soc. Bangladesh (Sci) X(2): 82-91.

HOQUE, B. and HABIB, A.H.M. SHAFIULLAH 2003. Influence of food on the growth and recruitment of oocytes in the stinging catfish, Heteropneustes fossilis (Bloch). $J$. Asiat. Soc. Bangladesh (Sci) 29(1): 71-78.

KAPOOR, C.P. 1977. Nucleolar extrusions in the oocytes of female Puntius ticto (Ham). $Z$. Mikrosk anat. Forsch. Leipzig. 90: 514-520.

KHAN, R.A. and SIDDIQUE, A.Q. 1973. Studies on the age and growth of Rohi (Labeo rohita) from a pond the rivers Ganga and of Yamuna. Proc. Indian Nat, Sci. Acad. B. Biol. Sci. 39(5): 582- 597.

LE CREN, E.D. 1958. Observations on the growth of perch (Perca fluviatilis L.) over twenty two years with special reference to the effects of temperature and change in population density. J. Anim. Ecol. 27: 287-2334.

MINA, M. V. 1965. On the development of a method of objective estimation of otolith zone structure. In Russian Vop. Ikhthyol. 5: 732-735.

RAO, K.V.S. 1961. Studies on the age determination of 'ghol' Pseudosciaena diacanthus (Lacepede) by means of scales and otoliths. Indian J. Fish. 8: 121-126.

SHAFI, M. and MAITLAND, A.G. 1971. The age and growth of perch (Perca fluviatillis L.) in two Scottish lochs. J. Fish. Biol. 3: 39-57.

SHAFI, M., QUDDUS, M.M.A. and HOQUE, B. 1977. Studies on the age and growth of Catla catla (Hamilton-Buchanan, 1822) from the Karnafully reservoir and Dhaka University pond. J. Asiatic. Soc. Bangladesh, Sc. 3(1): 47-68.

SINHA, V.R.P. and JONES, J.W. 1967. On the age and growth of the freshwater eel (Anguilla anguilla). J. Zool. 153: 99-117.

VILLANEUVA, R. and BALBINE, M. 1997. Validation of the otolith increment deposition ratio using alizarin marks in juveniles of the sparid fishes, Diplodas vulgaris and $D$. puntazzo, Fisheries Research (Amsterdam). 30(30): 257-260.

WALDRAN, M.E. and GERNEKE, D.A. 1997. Comparisons of two scanning electron microscope, techniques for examining daily growth increments on fish otolith. $J$. Fish Biol. 50(2): 450-454. 